Research Article

\title{
Viscoelastic-Viscoplastic Modelling of the Scratch Response of PMMA
}

\author{
G. Kermouche, ${ }^{1}$ N. Aleksy, ${ }^{2}$ and J. M. Bergheau ${ }^{2}$ \\ ${ }^{1}$ Ecole Nationale Supérieure des Mines de Saint-Etienne, SMS Division, LGF UMR CNRS 5307, \\ 158 Cours Fauriel 42023 Saint-Etienne Cedex, France \\ ${ }^{2}$ Université de Lyon, ENISE, LTDS UMR CNRS 5513, 58 Rue Jean Parot, 42023 Saint-Etienne Cedex 2, France
}

Correspondence should be addressed to G. Kermouche; kermouche@emse.fr

Received 28 November 2012; Revised 18 January 2013; Accepted 18 January 2013

Academic Editor: Pavel Lejcek

Copyright (C) 2013 G. Kermouche et al. This is an open access article distributed under the Creative Commons Attribution License, which permits unrestricted use, distribution, and reproduction in any medium, provided the original work is properly cited.

\begin{abstract}
This paper aims at understanding how to model the time-dependent behavior of PMMA during a scratch loading at a constant speed and at middle strain levels. A brief experimental study is first presented, consisting of the analysis of microscratches carried out at various scratching velocities and normal loads. The loading conditions have been chosen in such a way that neither (visco)elasticity nor (visco)plasticity of the PMMA may be neglected a priori. The main analyzed parameter is the tip penetration depth measured during the steady state. Then, a finite element model is used to investigate the potential of classical elastic-viscoplastic constitutive models to reproduce these experimental results. It is mainly shown that these models lead to unsatisfying results. More specifically, it is pointed out here that the time-independent Young modulus used in such models is not suitable. To take into account this feature, a viscoelastic-viscoplastic model based on the connection in series of a viscoelastic part with a viscoplastic part is proposed. It is shown that it leads to more acceptable results, which points out the importance of viscoelasticity in the scratch behavior of solid polymers.
\end{abstract}

\section{Introduction}

The scratch test is one of the most efficient tests to investigate the mechanical resistance of coated and uncoated surfaces [13]. In a typical single pass scratch test, a hard indenter slides along the surface of a relatively soft material (see Figure 1). Depending on the materials and on the scratch conditions, crack propagations $[4,5]$ and/or elastic-plastic deformations are observed $[6,7]$. The scratch test on amorphous polymers has been widely investigated during the past ten years [814], because of the large use of amorphous polymer films as surface protection in many industrial sectors. It is now well known that the scratch resistance of amorphous polymers depends on the scratching speed and on the load applied on the tip $[15,16]$. It points out their complex mechanical behavior which depends strongly on strain and strain rate levels and on the temperature. Three kinds of constitutive models are commonly used: viscoelastic models [17] for low strain levels, elastic-viscoplastic models [18] for large strain levels, and viscoelastic-viscoplastic models [19] for middle strain levels. These different strain levels are illustrated in
Figure 2. In the case of scratch loadings, it is difficult to state on the appropriate model to use $[20,21]$. Indeed, depending on the scratch conditions, the strain levels can be very different, and thus different phenomena have to be taken into account to really understand the scratch behavior of such materials. For instance, one issue addresses the necessity to take into account the viscoelasticity at small strains. One other issue could concern the influence of the strain softening or the effect of the hyperelastic hardening on the scratch results. The present paper focuses on the time-dependent properties (viscoelasticity, viscoplasticity) of the PMMA and their relation to the scratch response. The aim of this paper is to determine which is the best model to reproduce the influence of the scratching speed induced by a rigid spherical indenter on a PMMA.

Such investigations cannot only be based on experimental measurements, because viscoelasticity and viscoplasticity may have a similar effect on the measured penetration depth, contact pressure, and friction coefficient [22] at given loads and scratching speeds. Finite element calculations appear as a great help for such an investigation because it allows to 


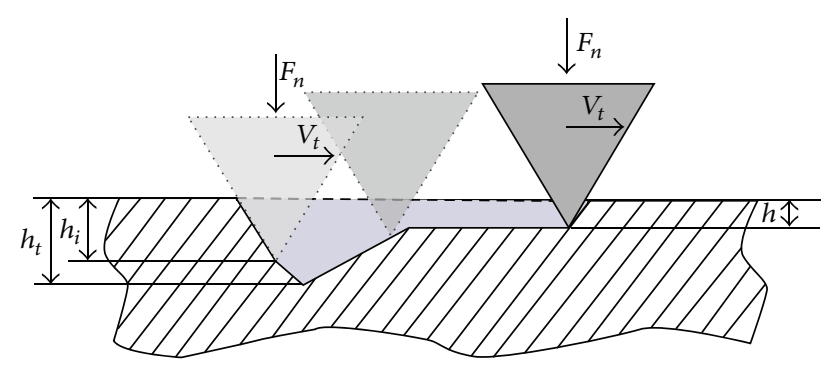

Figure 1: Penetration during load controlled scratch test.

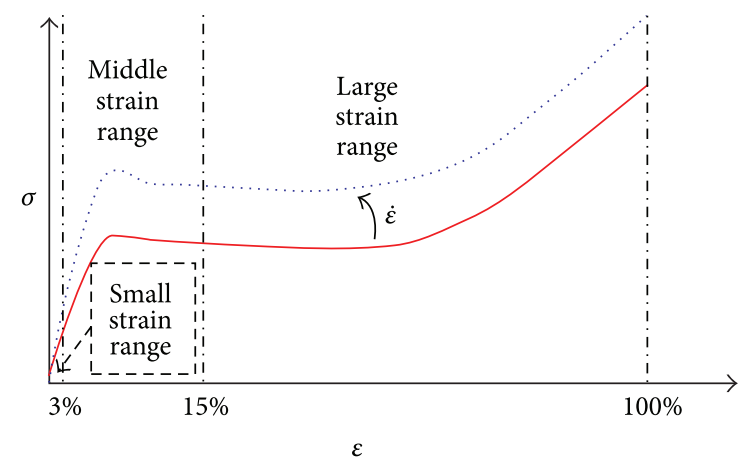

FIGURE 2: Stress/strain curve of amorphous glassy polymers in tensile test: the small strain level corresponds to linear viscoelasticity, the large strain level can be well described by an elasticviscoplastic model, and the middle strain level should account for both viscoelasticity and viscoplasticity.

understand the own influence of each material property on the scratch response. The finite element method has often been used in the past to understand phenomena occurring during scratch tests on semi-infinite homogeneous solids $[6,7,13,20,23-25]$ or on coating over substrate systems $[3,26,27]$. Here, we propose a coupled experimental and numerical investigation to address this issue.

Let us now describe the scratch test realized. At fixed normal load, penetration of the tip increases during the indentation stage up to the static mechanical balance. When the tip begins its tangential displacement, the contact area decreases by the rear face of the tip. That leads to a new increase of the penetration depth to satisfy the static mechanical balance. Then, a frontal ridge is created and grows until the steady state is reached, which leads also to a decrease of the penetration depth (Figure 1). The analysis of this transient regime is very difficult because it depends both on the kinematics of the indentation stage and on the scratch stage. Moreover, the static adhesion should also have a strong influence. Consequently, in this paper, only the results in the steady state are investigated.

This paper is splitted into a brief experimental part and a modelling part. The experimental approach consists in the analysis of microscratches carried out on PMMA samples at different scratching velocities and at different normal loads. The loading conditions have been chosen in such a way that neither the (visco)elasticity nor (visco)plasticity of the
PMMA may be neglected a priori. The main analyzed parameter is the penetration depth of the tip measured during the steady state. The modeling part aims at determining the constitutive model that can reproduce the experimental results with enough accuracy. First, the standard elastic-viscoplastic model developed by Argon and later improved by Arruda and Boyce ( $\mathrm{AB}$ model in the sequel) is used. It is shown that this model is not accurate enough. More specifically, it is pointed out here that the time-independent Young modulus used in such models is not suitable. To take into account this feature, a viscoelastic-viscoplastic model based on the connection in series [22] of the classical viscoelastic model and the $A B$ viscoplastic model is proposed. It is shown that this model leads to more acceptable results. Finally, we conclude on the importance to take into account viscoelasticity to model the scratch behavior of solid polymers.

\section{Experimental Study}

2.1. Scratch Experiments. The scratch tests are performed with the nanoindenter XP from Agilent. This device is set on an air table, and the whole system is installed in a thermal room. The temperature, the normal load, and the scratch velocity are controlled [28]. The penetration depth of the tip is measured. Two samples of PMMA from two different suppliers are scratched three times in the same conditions in order to ensure the stability and the reproducibility of the results. Nine series of microscratch are carried out for three normal loads, $F_{n}=20 \mathrm{mN}, F_{n}=40 \mathrm{mN}$, and $F_{n}=80 \mathrm{mN}$, and three tip velocities $V=0.1 \mu \mathrm{m} \cdot \mathrm{s}^{-1}, V=1 \mu \mathrm{m} \cdot \mathrm{s}^{-1}$, and $V=10 \mu \mathrm{m} \cdot \mathrm{s}^{-1}$ with a spherical tip (radius $R=35 \mu \mathrm{m}$ ). The whole experiments are performed at the room temperature $\left(T=25^{\circ} \mathrm{C}\right)$ with the scratch distance of $100 \mu \mathrm{m}$. The steady state has been reached for each scratch. The results are summarized in Table 1. The measured friction coefficient is about 0.15 for each scratch.

2.2. Analysis. As shown in Table 1, the penetration depth is maximum for the highest normal load and the lowest scratching speed used. According to many authors [20,29], the average strain level induced by a scratch test can be estimated using the same formula as for indentation test

$$
\varepsilon_{r}=\kappa \frac{a}{R}
$$

where a is the contact radius and $\kappa$ is a coefficient. For indentation test, $\kappa$ is about 0.2 whereas for scratch test $\kappa$ is about $0.5-1$. Neglecting piling up or sinking-in phenomena, the contact radius $a$ equals to the geometrical contact radius $a_{c}$ which may be estimated directly from penetration depth $h$ by the following equation:

$$
a_{c}=\sqrt{h(2 R-h)} .
$$

Here, the ratio $a_{c} / R$ is about $0.25-0.35$. According to Pelletier et al. [29], it corresponds to the middle strain level for PMMA, where both viscoelasticity and viscoplasticity may affect the scratch response of the PMMA. Let us also note that at such a strain level, the hyperelastic hardening has a very weak 
TABLE 1: Penetration depth measured for different scratching speeds and different load applied.

\begin{tabular}{lccc}
\hline$F_{n}$ in $\mathrm{mN}$ & $V=0.1 \mu \mathrm{m} / \mathrm{s}$ & $V=1 \mu \mathrm{m} / \mathrm{s}$ & $V=10 \mu \mathrm{m} / \mathrm{s}$ \\
\hline 20 & $870 \pm 10$ & $800 \pm 8$ & $730 \pm 9$ \\
40 & $1550 \pm 10$ & $1420 \pm 8$ & $1280 \pm 8$ \\
80 & $2780 \pm 12$ & $2540 \pm 10$ & $2240 \pm 11$ \\
\hline
\end{tabular}

influence on the PMMA mechanical response contrary to viscoelasticity.

Let us now focus on the effect of the scratch speed: the results summarized in Table 1 point out that whatever the normal load is, $h$ decreases when $V$ increases. Consequently, the contact area should also decrease when $V$ increases, which indicates that the mean contact pressure-usually called hardness-increases with the tip velocity. As shown in previous papers $[3,22]$, the increase in mean contact pressure with scratching speed is a clue that the scratched material exhibits a time-dependent behavior. This could be explained with the help of the scratch representative parameters as shown by Aleksy et al. [22]. Similarly to indentation testing $[30,31]$, the representative stress is proportional to the mean contact pressure. According to Briscoe et al. [32], the representative strain rate is given by

$$
\dot{\varepsilon}_{r} \propto \frac{V}{a_{c}} .
$$

For a given normal load, the increase in $V$ leads to a decrease in $a_{c}$ and, according to (3), an increase in $\dot{\varepsilon}_{r}$. As the mean contact pressure also increases when $V$ increases, it points out that the representative stress depends on the representative strain rate. Consequently, the PMMA exhibits a timedependent behavior during such a scratch test. As shown by Aleksy et al. [22], both viscoelasticity and viscoplasticity may lead to the same result. The aim of the following section is to state whether viscoelasticity and/or viscoplasticity are the the most suitable models to describe the scratch behavior of PMMA at such middle strain levels.

As a preliminary conclusion, this experimental study points out that the mechanical behavior of the PMMA depends on the representative strain rate during the scratch test which is in good agreement with the literature on this subject $[8,32]$ and also with the tensile and compressive behavior of this well-known time-dependent material.

\section{Numerical Investigation}

The aim of the numerical investigation is to determine the best model which reproduces the experimental variation of steady state penetration depth $h$ with the tip velocity. Experiments have highlighted the time-dependent behavior of the PMMA. As microscratches at such strain levels involve residual grooves [29], therefore the simplest model to be employed is an elastic-viscoplastic one. However, the Young modulus of the glassy amorphous polymers is well known to depend on the strain rate, which is an evidence of a viscoelastic behaviour. In this section, we try to adress the following

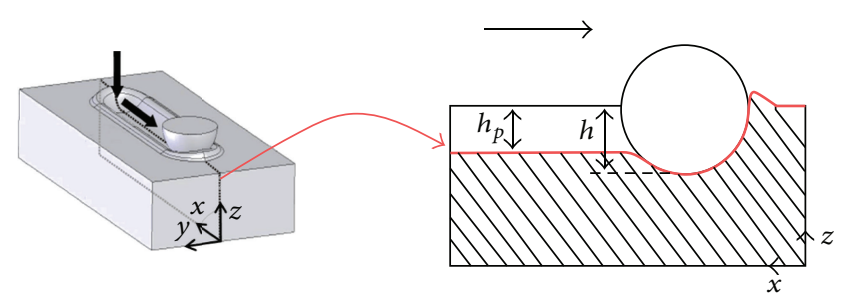

FIgURE 3: Representation of the zx symmetry cut plane.

issue: Is the elastic-viscoplastic model accurate enough or is it necessary to use a combined viscoelastic-viscoplastic model?

3.1. Numerical Model. The simulation of a scratch test on a polymeric material is nontrivial because of two major numerical problems: contact with friction under large displacement and large deformations which could induce severe mesh distortions. All of these problems have been treated in previous articles $[3,7,22]$, and this is the reason why they are not described in details in the present paper, to focus on the main goal of this work: the mechanical behaviour of PMMA under a scratch loading.

The scratch test presents a symmetry plane, $y=0$, defined by the indentation $z$-axis and the scratching $x$-axis (Figure 3 ). Consequently, the numerical study can be carried out on half of the domain. The finite element domain is a right angled parallelepiped.

The dimensions of this domain have been chosen high enough to avoid boundary effects. The mesh is constituted of 8-node-brick isoparametric element with selective-reduced integration scheme to ensure plastic incompressibility. The numerical simulations are performed using a large displacement/large strain option (updated Lagrangian formulation). To increase the computation accuracy and to limit the computation time, the mesh is refined in the vicinity of the scratch. The contact and friction inequalities are solved using the penalty method [33]. For very low levels of scratching conditions (small penetration compared to tip radius, low friction coefficient), numerical simulations can be performed without remeshing algorithm. Let us note that an automatic remeshing procedure was implemented in the finite element software Systus to study more severe scratching conditions [3].

Similarly to the experimental study, the tip radius is $R=$ $35 \mu \mathrm{m}$, the temperature is $T=25^{\circ} \mathrm{C}$, the tip velocities are $V=$ $0.1 \mu \mathrm{m} \cdot \mathrm{s}^{-1}, V=1 \mu \mathrm{m} \cdot \mathrm{s}^{-1}$, and $V=10 \mu \mathrm{m} \cdot \mathrm{s}^{-1}$, and the normal load is constant and identical to the experimental one $\left(F_{n}=\right.$ $20 \mathrm{mN}, F_{n}=40 \mathrm{mN}$ and $F_{n}=80 \mathrm{mN}$ ). However, the numerical loading is achieved by controlling the quasistatic displacement of the indenter. A specific algorithm has thus been developed in the finite element software (Systus) to ensure the control of the load. It adjusts the vertical displacement to maintain the normal load constant, at each time step. Let us note that the adhesion friction coefficient (Coulomb) is adapted at each velocity and each normal load to exactly reproduce the friction coefficient measured during the experimental microscratches $\left(\mu_{\text {measured }}=\mu_{\text {adhesion }}+\mu_{\text {ploughing }}\right.$ $[2,34])$. 


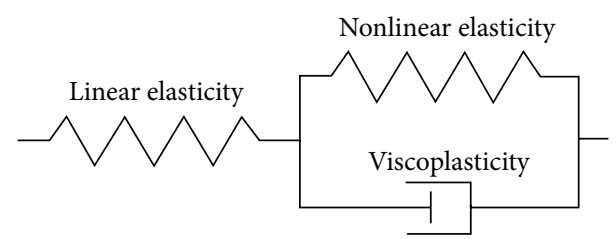

Figure 4: Standard rheology used to describe the large strain range of glassy polymers [18].

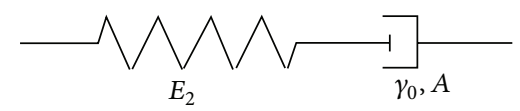

FIGURE 5: Arruda-Boyce model without the strain hardening element.

3.2. Elastic-Viscoplastic Modeling. Typical tensile stress/strain curves obtained for amorphous glassy polymers are represented in Figure 2. This mechanical behavior can be easily described with an elastic-viscoplastic formulation [35-37]. Such model can be constituted by three rheological elements connected as in Figure 4. The first spring represents the linear elasticity referring to the behavior at small strains. The dashpot, here assumed as a viscoplastic element, represents the time-dependence yield stress and the strain softening of such materials in plastic regime. The second spring refers to the nonlinear elastic strain hardening of amorphous polymers, which is similar to the hyperelastic behavior of elastomeric materials $[18,38,39]$.

3.2.1. Constitutive Model. The PMMA elastic-viscoplastic behavior is here modeled with the modified Arruda-Boyce model [18, 40, 41]. It is composed of an Argon viscosity [42], in parallel with a Langevin rubbery hyperelasticity. This element, used to model the strain hardening, is not accounted for in the present paper because we have observed that for a scratch severity lower than $a_{c} / R=0.4$, the strain level is not high enough to activate this element. Finally, a linear elasticity is added in, series in order to model the behavior at small strains (Figure 5). Scalar equation of the Argon viscous element is written:

$$
\dot{\gamma}^{p}=\dot{\gamma}_{0} \exp \left[\frac{A}{k T}(\tau-s)\right],
$$

where $\dot{\gamma}^{p}$ is the plastic shear strain rate, $\dot{\gamma}_{0}=2.8 \cdot 10^{7} \mathrm{~s}^{-1}$ and $A=1.39 \cdot 10^{-27}$ are material constants, $\tau$ is the effective equivalent shear strength, $k$ is Boltzmann's constant, $T$ is absolute temperature, and $s$ is the athermal shear strength. This strength $s$ varies during strain softening according to

$$
\dot{s}=\xi\left(1-\frac{s}{s_{\mathrm{ss}}}\right) \dot{\gamma}^{p}
$$

where $\xi=315 \mathrm{MPa}$ is the softening slope, $s_{\max }=0.077 \mathrm{G} /(1-$ $v)$ is the athermal shear strength without strain softening, and $s_{\mathrm{ss}}$ is the preferred state of the material $\left(s_{\mathrm{ss}} / s_{\max }=0.87\right)$. $G$ is the elastic shear modulus, and the Poisson ratio is assumed to be constant and equal to 0.33. Different values of the Young

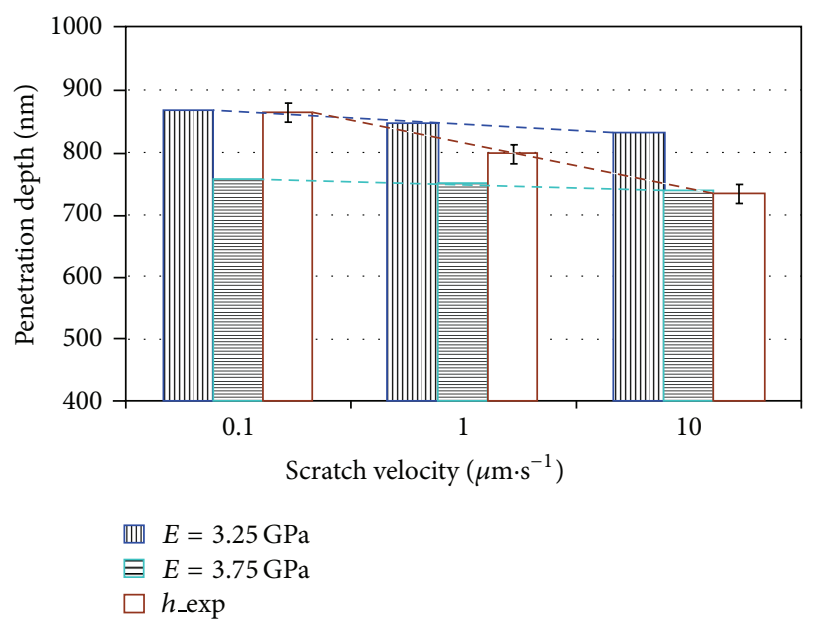

FIGURE 6: Comparison of experimental results ( $h_{-}$exp) and numerical results for $F_{n}=20 \mathrm{mN}$. The data denoted by $E=3.25 \mathrm{GPa}$ (resp., $E=3.75 \mathrm{GPa}$ ) are those calculated with the elastic-viscoplastic model in using a Young modulus of 3.25 GPa (resp., 3.75 GPa).

modulus have been used in order to highlight its effect on the scratch response. More specifically, two different values have been used at each normal load. They have been chosen in order to fit the experiments for the lowest and highest scratch speeds. The numerical results constitute the upper bound and lower bound of the experiments. These values are consistent with the classical value of the Young modulus of the PMMA [43-45].

3.2.2. Numerical Results. The variation of the penetration depth with the scratch speed is shown in Figure 6 for $F_{n}=$ $20 \mathrm{mN}$. The data denoted that $h_{-} \exp$ corresponds to the experimental data whereas $E=3.25 \mathrm{GPa}$ (resp., $E=$ 3.75 $\mathrm{GPa}$ ) are those calculated with the FEM model in using a Young modulus of $3.25 \mathrm{GPa}$ (resp., 3.75 GPa).

One can firstly observe that the slope of the decrease of the penetration depth calculated with the FEM is less pronounced than the experimental one. It means that the timedependent behavior of the PMMA is not well reproduced with this elastic-viscoplastic model in these conditions $\left(F_{n}\right.$ and $V$ ). One can also observe that the Young modulus has to be adapted to the tip velocity (i.e., to say the representative strain rate) to fit the experimental data. Figures 7 and 8 show the penetration depth in different tip velocities for $F_{n}=$ $40 \mathrm{mN}$ and $F_{n}=80 \mathrm{mN}$. Here again, the same conclusions can be drawn.

The major assumption in this study is that the Young modulus remains time independent. However, this parameter is well known to depend on the strain rate for most polymers in particular for the PMMA $[45,46]$. This aspect could explain the bad agreement between experimental and numerical results. Such phenomenon is often modeled by using a viscoelastic model [47].

It can also be observed that the Young modulus which fits the experimental variation depends also on the value of the normal load used. For instance, a Young modulus of $3.75 \mathrm{GPa}$ is required to fit the penetration depth corresponding to 


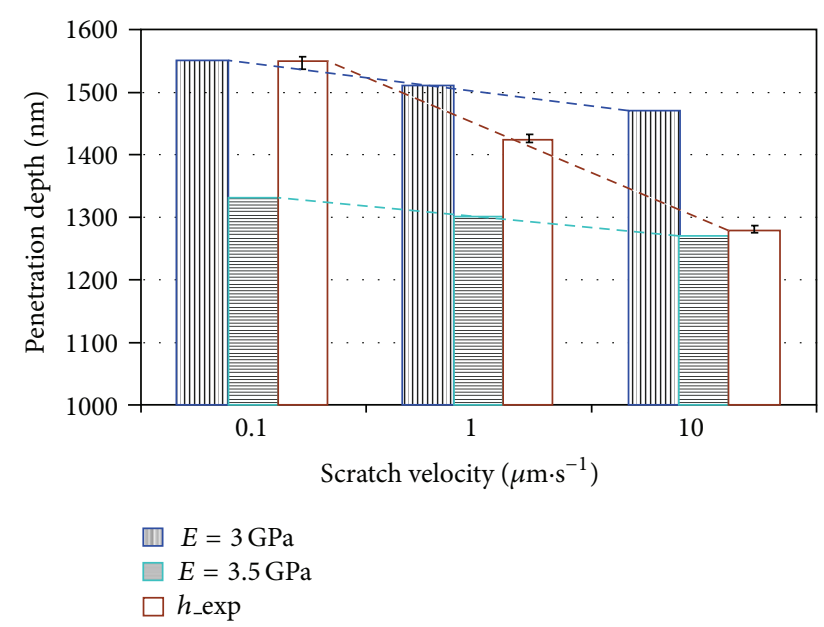

FIGURE 7: Comparison of experimental results $\left(h_{-} \exp \right)$ and numerical results for $F_{n}=40 \mathrm{mN}$. The data denoted by $E=3.0 \mathrm{GPa}$ (resp., $E=3.5 \mathrm{GPa}$ ) are those calculated with the elastic-viscoplastic model in using a Young modulus of $3.0 \mathrm{GPa}$ (resp., 3.5 GPa).

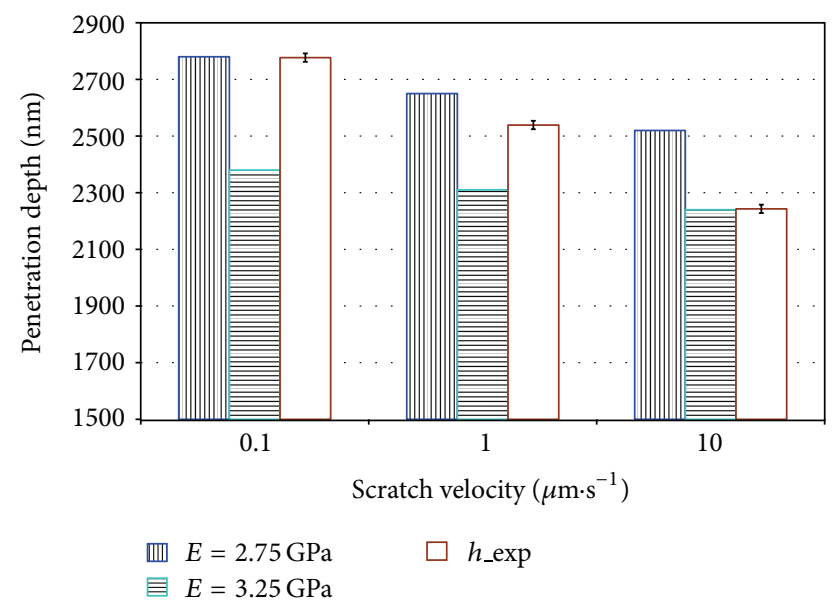

FIGURE 8: Comparison of experimental results ( $h_{-}$exp) and numerical results for $F_{n}=80 \mathrm{mN}$. The data denoted by $E=2.75 \mathrm{GPa}$ (resp., $E=3.25 \mathrm{GPa}$ ) are those calculated with the elastic-viscoplastic model in using a Young modulus of 2.75 GPa (resp., 3.25 GPa).

$V=10 \mu \mathrm{m} \cdot \mathrm{s}^{-1}$ and $F_{n}=20 \mathrm{mN}$, whereas a Young modulus of $3.25 \mathrm{GPa}$ is required to fit the penetration depth corresponding to $V=10 \mu \mathrm{m} \cdot \mathrm{s}^{-1}$ and $F_{n}=80 \mathrm{mN}$. Here again, this result is consistent with a viscoelastic behavior, since the elastic modulus depends on the strain rate [22]. Indeed, the higher the load, the higher the contact radius and according to (3), the lower the representative strain rate and thus the lower the elastic modulus. However, prior to start a more complex viscoelastic-viscoplastic investigation, we have studied the influence of the viscoplastic parameters on the penetration depth. Indeed, the set of the parameters used here has been identified by Arruda and Boyce [18] from macroscopic compression testing and thus, it could be not appropriate to model the response of our PMMA samples at such a microscopic scale.
3.2.3. A New Set of Viscoplastic Parameters. In this section, we attempt to fit the experimental data by modifying the viscoplastic parameters of Arruda-Boyce model [18]. The strategy consists in determining the values of theses parameters leading to the closest results to $h_{-} \exp$ for $F_{n}=20 \mathrm{mN}$. Then, this set of parameters is used to simulate microscratches at $F_{n}=40 \mathrm{mN}$ and $F_{n}=80 \mathrm{mN}$, and the results are compared with experiments.

The first step deals with the determination of the Young modulus. The original value provided by Arruda and Boyce [18] is $E=3.2 \mathrm{GPa}$. By applying the elastic theory of Hertz given by (6), the penetration depth in the case of a purely linear elastic contact should be equal to $h=800 \mathrm{~nm}$ at $F_{n}=$ $20 \mathrm{mN}$ :

$$
h_{\text {elastic }}=\left(\frac{3}{4} \frac{F}{E^{\star}} \sqrt{R}\right)^{2 / 3} \quad \text { with } E^{\star}=\frac{E}{1-v^{2}} .
$$

The elastic behavior constitutes the limit state of the elastic-viscoplastic framework for extremely high strain rate. In our study that means that elastic simulations lead necessary to less deep penetration than elastic-viscoplastic simulations, for identical Young modulus. However, elastic theory provides $h=800 \mathrm{~nm}$ (with $E=3.2 \mathrm{GPa}$ ) which is deeper than experimental penetration. It can thus be concluded that $E=3.2 \mathrm{GPa}$ cannot be applied. $E=3.75 \mathrm{GPa}$ appears to be the most accurate value (for $F_{n}=20 \mathrm{mN}$ ).

The second step consists in determining the most suitable set of parameters of the viscoplastic element. This element is governed by (4) rewritten as

$$
\tau=s+\frac{k}{A} T \ln \left(\frac{\dot{\gamma}^{p}}{\dot{\gamma}_{0}}\right) .
$$

The modification of parameters $A$ and $\dot{\gamma}_{0}$ alters the viscoplastic response. $A$ modifies the sensitivity to the strain rate, and $\dot{\gamma}_{0}$ is the strain rate corresponding to the athermal shear stress $s$. Several scratch simulations have been carried out for $F_{n}=20 \mathrm{mN}$ with various values of $A$ and $\dot{\gamma}_{0}$. The best results according to experiments are shown in Figure 9. They have been obtained with: $A=1.956 \cdot 10^{-27} \mathrm{~m}^{3}$ and $\dot{\gamma}_{0}=$ $300 \mathrm{~s}^{-1}$. One can observe the penetration depth in different tip velocities. A very good agreement is obtained between numerical and experimental results. Before concluding about the accuracy of this elastic-viscoplastic model, this result needs to be confirmed for the other normal loads.

Two series of simulations have been thus carried out at $F_{n}=40 \mathrm{mN}$ and $F_{n}=80 \mathrm{mN}$ with this particular set of parameters $\left(E=3.75 \mathrm{GPa}, A=1.956 \cdot 10^{-27} \mathrm{~m}^{3}\right.$, and $\dot{\gamma}_{0}=$ $\left.300 \mathrm{~s}^{-1}\right)$. Figures 10 and 11 show the penetration depth obtained in this way compared to the experimental one. Firstly, the numerical penetration at each tip velocity and each normal load is significantly different to the experimental one. Secondly, the variation of the numerical penetration depth with the tip velocity at each normal load does not reproduce the experimental one. As a conclusion, this elasticviscoplastic model is not appropriate even after the adjustment of its parameters. In this context, we propose to investigate the addition of a viscoelastic model to this viscoplastic one. 


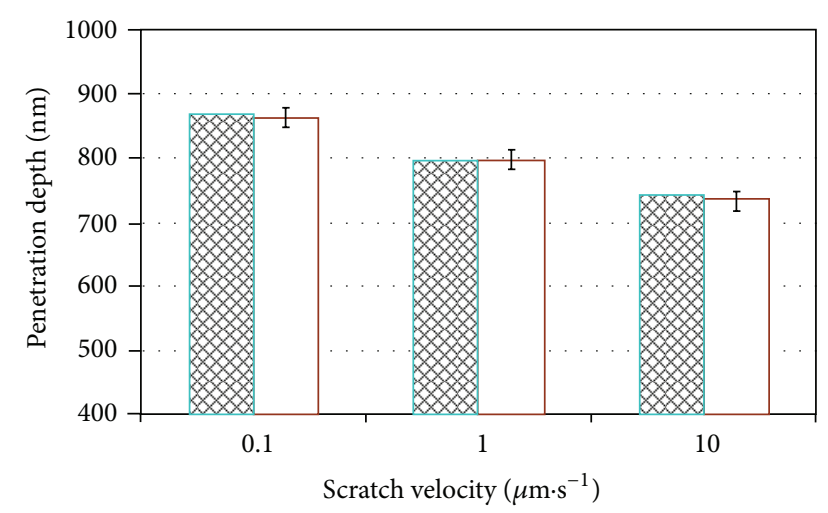

区 fit EVP

$\square h \_\exp$

FIgURE 9: Comparison of experimental results ( $\left.h_{-} \exp \right)$ and numerical results (fit_EVP) for $F_{n}=20 \mathrm{mN}$. The numerical results have been obtained with the elastic-viscoplastic model in using a Young modulus of $3.75 \mathrm{GPa}$. The set of parameters have been identified from experimental scratch results at $20 \mathrm{mN}$.

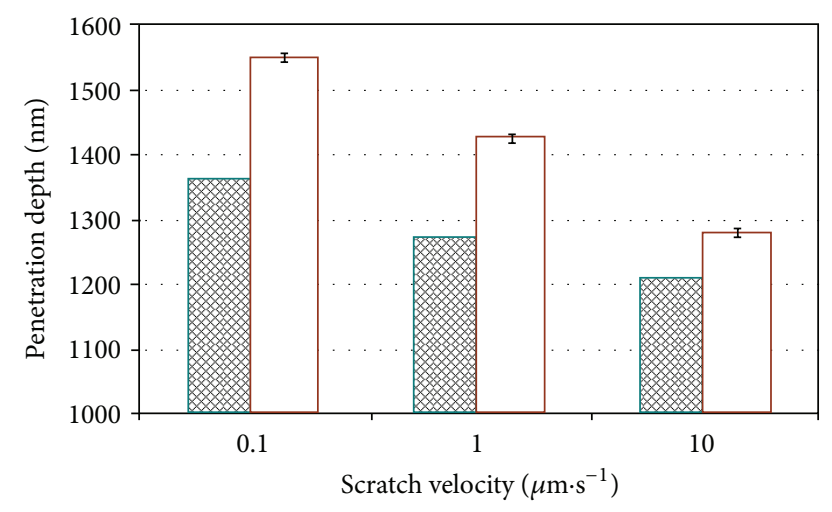

网 fit EVP

$\square h_{-} \exp$

Figure 10: Comparison of experimental results ( $h_{-} \exp$ ) and numerical results (fit_EVP) for $F_{n}=40 \mathrm{mN}$. The numerical results have been obtained with the elastic-viscoplastic model in using a Young modulus of $3.75 \mathrm{GPa}$. The set of parameters have been identified from experimental scratch results at $20 \mathrm{mN}$.

3.3. Viscoelastic-Viscoplastic Model with the "Series Model". To account for both viscoelasticity and viscoplasticity, we have developed a specific algorithm [22], named "series model" in the finite element code Systus. It makes it possible to connect in series two models of any kind (Figure 12). Such algorithm is helpful to combine very quickly whatever models, if their constitutive equations are available in the finite element code in the same framework (updated lagrangian, total lagrangian, etc.). The algorithm uses an iterative process which calculates the dispatching of the strain rate to ensure the equality of the stress tensors. This algorithm can be summarized as in Figure 13. Our case study needs to connect a viscoelastic model with a viscoplastic one.

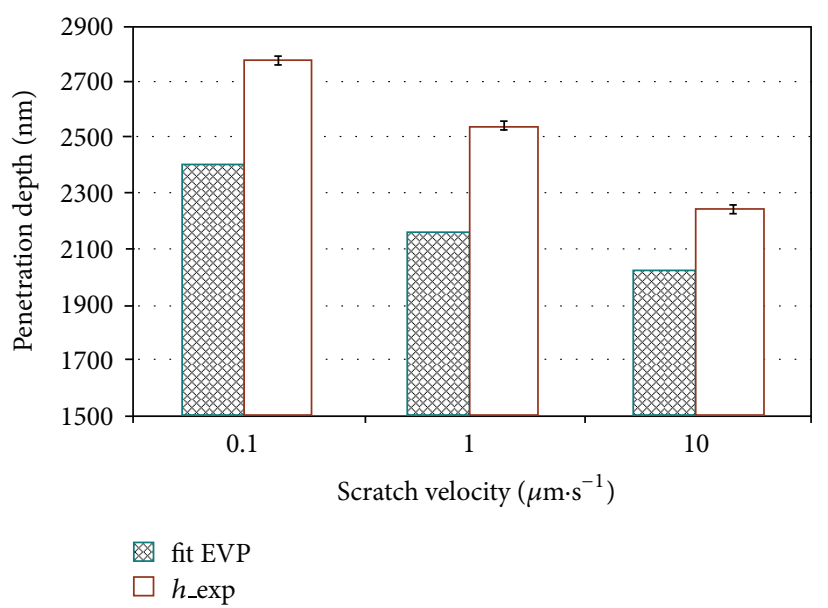

FIGURE 11: Comparison of experimental results ( $\left.h_{-} \exp \right)$ and numerical results (fit_EVP) for $F_{n}=80 \mathrm{mN}$. The numerical results have been obtained with the elastic-viscoplastic model in using a Young modulus of $3.75 \mathrm{GPa}$. The set of parameters have been identified from experimental scratch results at $20 \mathrm{mN}$.

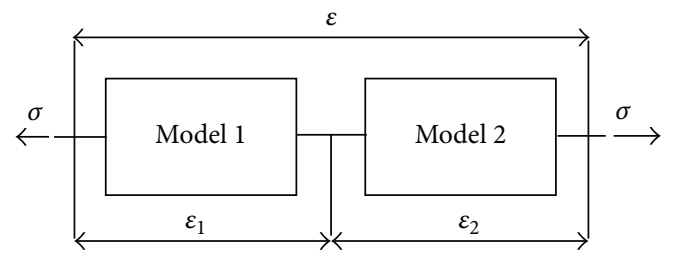

FIgURE 12: Connection in series of two rheological models.

3.3.1. The Viscoelastic-Viscoplastic Model. In our case study, model 1 refers to the Kelvin-Voigt model and model 2 corresponds to the Arruda-Boyce model previously presented in Figure 14. However, the viscoelastic response of the whole model is the consequence of the connection in series of the Kelvin-Voigt model and the elastic element of ArrudaBoyce model. That constitutes the Poynting model having a viscoelastic transition wide enough to cover the sharp experimental velocities range (only two decades) and the parameters used in the viscoelastic model derived from the elasticviscoplastic simulations. More precisely, the values of the Young modulus chosen in the previous section can be considered as the instantaneous and delayed modulus of the viscoelastic model (Figure 14). The viscous parameter $\eta$ is identified by choosing the best fit to the experimental results at each normal load. The parameters are given in Table 2. One can observe that $\eta$ increases with the normal load $F_{n}$. This is meaningful because $E_{1}$ and $E_{2}$ also depend on the normal load as observed in the previous section. At a fixed tip velocity, the representative strain rate decreases when $F_{n}$ increases. Consequently, the range of strain rate shifts toward low values when $F_{n}$ increases, and thus, a higher viscous parameter is required.

3.3.2. Numerical Results. Figure 15 shows the penetration depth in different scratching velocities at $F_{n}=20 \mathrm{mN}$. First, the variation of the viscoelastic-viscoplastic penetration 


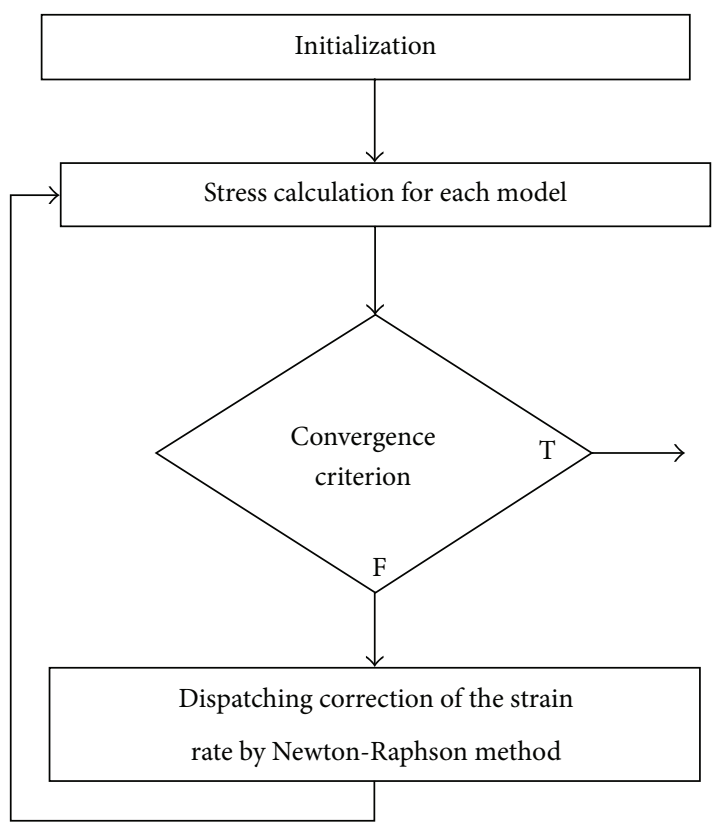

FIGURE 13: Series model algorithm.

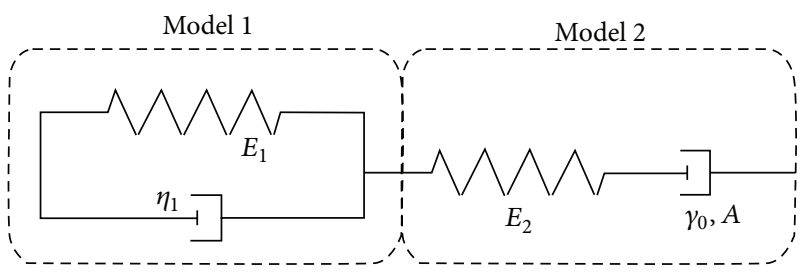

FIgURE 14: Proposed viscoelastic-viscoplastic model.

TABle 2: Parameters of the Kelvin-Voigt viscoelastic model.

\begin{tabular}{lccc}
\hline$F_{n}$ in $\mathrm{mN}$ & $E_{1}$ in $\mathrm{MPa}$ & $E_{2}$ in $\mathrm{MPa}$ & $\eta$ in $\mathrm{GPa} \cdot \mathrm{s}^{-1}$ \\
\hline 20 & 3250 & 3750 & 300 \\
40 & 3000 & 3500 & 500 \\
80 & 2750 & 3250 & 700 \\
\hline
\end{tabular}

VEVP is almost the same as the experimental one. Moreover, the viscoelastic-viscoplastic penetration VEVP at each tip velocity is very close to the experimental one. That means that the time-dependent behavior of the PMMA in scratch test is better reproduced with this viscoelastic-viscoplastic model. Figures 16 and 17 show the penetration depth in different scratching velocities at $F_{n}=40 \mathrm{mN}$ and at $F_{n}=80 \mathrm{mN}$. The same conclusions can be drawn: this viscoelastic-viscoplastic model is a pertinent solution to model the time-dependent scratch response of the PMMA. But how does this model modify the response to conventional testing? To adress this question, the shear stress-strain curves found by numerical simulation is plotted in Figure 18 using the set of parameters identified. The strain rate dependence of the yield stress level appears to be much pronounced than the strain rate dependence of the elastic modulus. Therefore, it could explain why

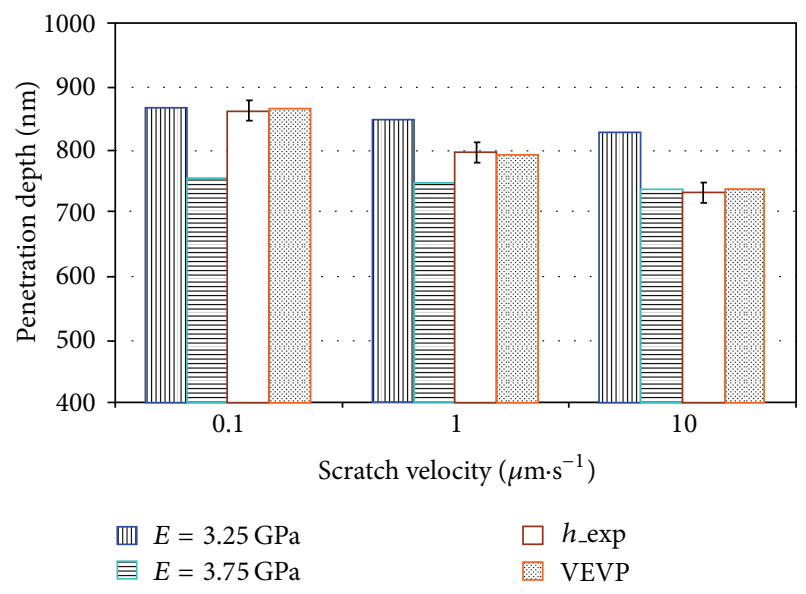

FIGURE 15: Comparison of experimental results ( $\left.h_{-} \exp \right)$ and numerical results (elastic-viscoplastic and viscoelastic-viscoplastic) for $F_{n}=20 \mathrm{mN}$. The data denoted by $E=3.25 \mathrm{GPa}$ (resp., $E=$ $3.75 \mathrm{GPa}$ ) are those calculated with the elastic-viscoplastic model in using a Young modulus of $3.25 \mathrm{GPa}$ (resp., 3.75 GPa). The data denoted VEVP corresponds to the viscoelastic-viscoplastic model.

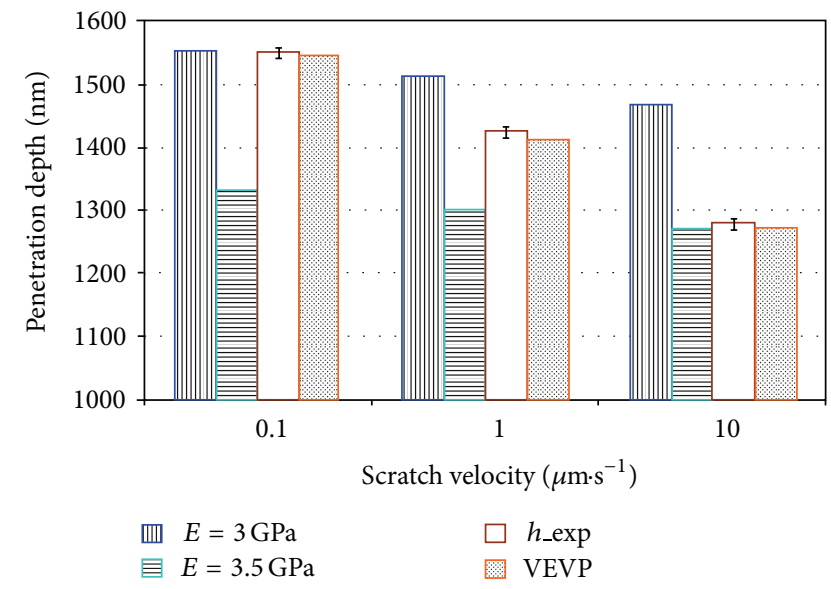

FIGURE 16: Comparison of experimental results ( $h_{-}$exp) and numerical results (elastic-viscoplastic and viscoelastic-viscoplastic) for $F_{n}=40 \mathrm{mN}$. The data denoted by $E=3.0 \mathrm{GPa}$ (resp., $E=3.5 \mathrm{GPa}$ ) are those calculated with the elastic-viscoplastic model in using a Young modulus of 3.0 GPa (resp., 3.5 GPa). The data denoted VEVP corresponds to the viscoelastic-viscoplastic model.

viscoelasticity has been often neglected in the past for investigating the scratch response of PMMA.

Let us pay attention that the viscoelastic model chosen here is too simplistic to be used in a more global context. In practice, it should be calibrated with the help of DMA testing, which should lead to the connection in series of another Kelvin-Voigt models. The aim of this paper was not to propose the right model of PMMA in scratch test, but to highlight that the understanding of the scratch behavior of PMMA at middle strain levels requires a viscoelastic-viscoplastic model. 


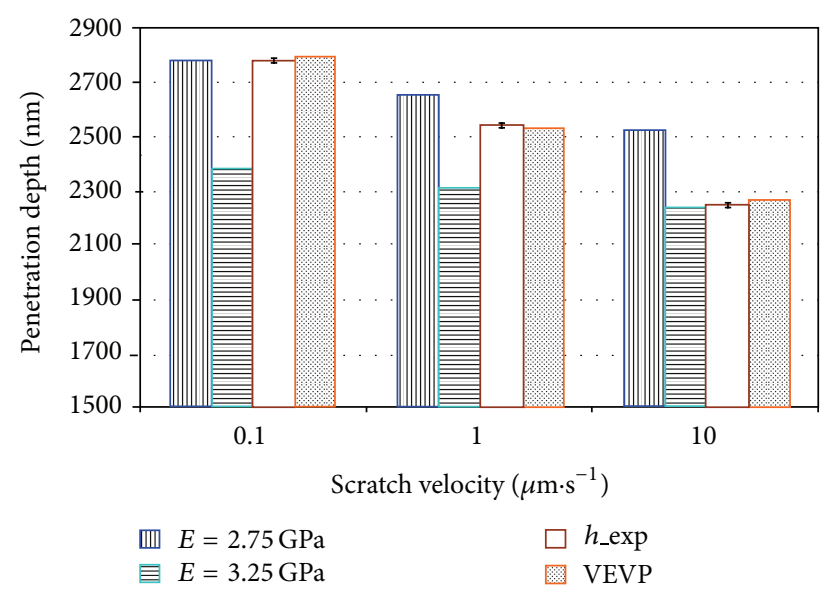

FIGURE 17: Comparison of experimental results ( $\left.h_{-} \exp \right)$ and numerical results (elastic-viscoplastic and viscoelastic-viscoplastic) for $F_{n}=80 \mathrm{mN}$. The data denoted by $E=2.75 \mathrm{GPa}$ (resp., $E=$ 3.25 $\mathrm{GPa}$ ) are those calculated with the elastic-viscoplastic model in using a Young modulus of $2.75 \mathrm{GPa}$ (resp., 3.25 GPa). The data denoted VEVP corresponds to the viscoelastic-viscoplastic model.

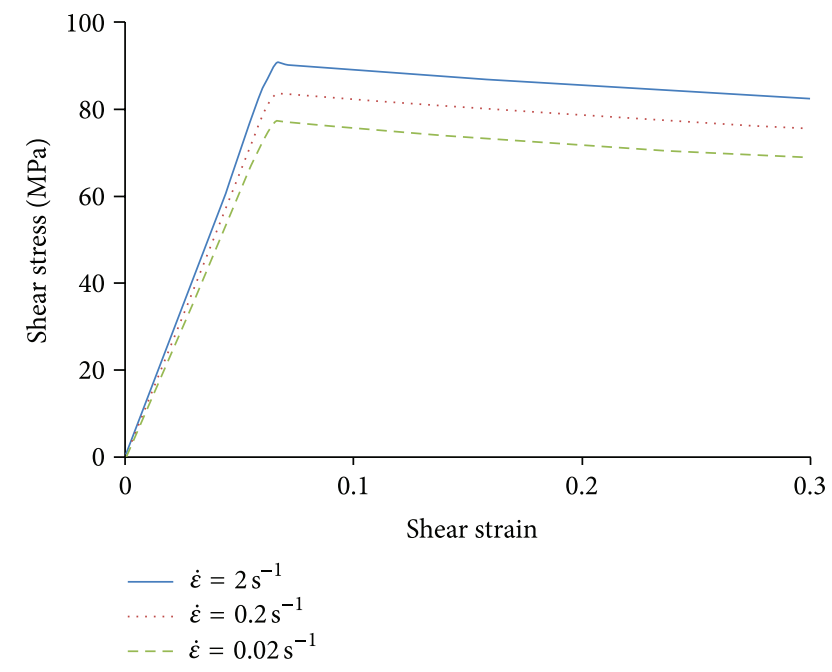

FIGURE 18: Shear stress-strain curves found by numerical simulation using the viscoelastic-viscoplastic model.

\section{Conclusions}

The investigation presented in this paper aims at understanding which is the best model to reproduce the time-dependent scratch behavior of PMMA at middle strain levels. A brief experimental study is first presented. It consists in the analysis of microscratches carried out on PMMA samples at different scratching velocities and at different normal loads. The loading conditions have been chosen in such a way that neitheir the (visco)elasticity nor (visco)plasticity of the PMMA may be neglected a priori. The main analyzed parameter is the penetration depth of the tip measured during the steady state. This experimental part is then followed by a modelling part which aims at determining the best constitutive model, elastic-viscoplatic or viscoelastic-viscoplastic, which allows to reproduce the experimental results. The standard elasticviscoplastic model developed by Argon and later improved by Arruda and Boyce is used. It is mainly shown that this model leads to non satisfying results. More specifically, it is pointed out here that the time-independent Young modulus used in such models is not suitable. To take into account this feature, a viscoelastic-viscoplastic model based on the connection in series of the classical viscoelastic model and the $A B$ viscoplatic model is proposed. It is shown that this model leads to more acceptable results, which points out the importance of viscoelasticity in the scratch behavior of solid polymers. Nevertheless, the viscoelastic model chosen here is too simplistic to be used in a more global context, because it only covers two decades of scratching speed. The goal of a forthcoming work could be to calibrate the viscoelastic parameters on a larger range in using a spectral approach based on DMA testing for instance.

The aim of this paper was not to propose the right model of PMMA in scratch test. It was to highlight the need to take into account both viscoelasticity and viscoplasticity to understand the scratch behavior of PMMA at middle strain levels. This observation is of primary importance in regards to the mechanical resistance of amorphous polymer films because the effect of viscoelasticity and viscoplasticity on the scratch results are not similar. This methodology can obviously be applied to other amorphous polymers such as PC or PS. One important perspective of this work is the possibility to use the scratch loading to identify the surface mechanical properties of solid polymers. Nevertheless, such investigations require to state on the influence of the mechanical properties affecting the response to a scratch loading to optimize the set of parameters to identify. Up to date, there is only a few papers dealing with this subject, mainly in reason of the difficulties related to the modeling of the scratch loading $[3,7,13,25,29]$. The present work can thus be viewed as a first step for this important issue.

\section{Acknowledgments}

The authors thank Professors J. L. Loubet and S. Pavan from Ecole Centrale de Lyon, France, for their help in the experimental part of this paper.

\section{References}

[1] V. Jardret, H. Zahouani, J. L. Loubet, and T. G. Mathia, "Understanding and quantification of elastic and plastic deformation during a scratch test," Wear, vol. 218, no. 1, pp. 8-14, 1998.

[2] D. Tabor, "Friction and wear-developments over the last fifty years," Mechanical Engineering Publications, vol. 1, pp. 157-172, 1989.

[3] G. Kermouche, N. Aleksy, J. L. Loubet, and J. M. Bergheau, "Finite element modeling of the scratch response of a coated time-dependent solid," Wear, vol. 267, no. 11, pp. 1945-1953, 2009.

[4] M. C. Baietto, J. Rannou, A. Gravouil, H. Pelletier, C. Gauthier, and R. Schirrer, "3D crack network analysis during a scratch test of a polymer: a combined experimental and multigrid $\mathrm{x}$-fem 
based numerical approach," Tribology International, vol. 44, no. 11, pp. 1320-1328, 2011.

[5] I. Demirci, C. Gauthier, and R. Schirrer, "Mechanical analysis of the damage of a thin polymeric coating during scratching: role of the ratio of the coating thickness to the roughness of a scratching tip," Thin Solid Films, vol. 479, no. 1-2, pp. 207-215, 2005.

[6] M. Barge, G. Kermouche, P. Gilles, and J. M. Bergheau, "Experimental and numerical study of the ploughing part of abrasive wear," Wear, vol. 255, no. 1-6, pp. 30-37, 2003.

[7] J. L. Bucaille, E. Felder, and G. Hochstetter, "Mechanical analysis of the scratch test on elastic perfectly plastic materials with the three-dimensional finite element modeling," Wear, vol. 249, no. 5-6, pp. 422-432, 2001.

[8] C. Gauthier, S. Lafaye, and R. Schirrer, "Elastic recovery of a scratch in a polymeric surface: experiments and analysis," Tribology International, vol. 34, no. 7, pp. 469-479, 2001.

[9] H. Pelletier Herve, A.-L. Durier, C. Gauthier, and R. Schirrer, "Viscoelastic and elastic-plastic behaviors of amorphous polymeric surfaces during scratch," Tribology International, vol. 41, no. 11, pp. 975-984, 2008.

[10] H. Pelletier, C. Gauthier, and R. Schirrer, "Influence of local friction coefficient and strain hardening on the scratch resistance of polymeric surfaces investigated by finite element modeling," Procedia Engineering, vol. 10, pp. 1772-1778, 2011.

[11] P. Bertrand-Lambotte, J. L. Loubet, C. Verpy, and S. Pavan, "Nano-indentation, scratching and atomic force microscopy for evaluating the mar resistance of automotive clearcoats: study of the ductile scratches," Thin Solid Films, vol. 398-399, pp. 306312, 2001.

[12] N. Aleksy, G. Kermouche, J. M. Bergheau, J. L. Loubet, and S. Pavan, "Mechanical investigation of the healing phenomenon of the PMMA," International Journal of Material Forming, vol. 3, no. 1, pp. 575-578, 2010.

[13] L. C. A. van Breemen, L. E. Govaert, and H. E. H. Meijer, "Scratching polycarbonate: a quantitative model," Wear, vol. 274, pp. 238-247, 2012.

[14] V. Jardret and P. Morel, "Viscoelastic effects on the scratch resistance of polymers: relationship between mechanical properties and scratch properties at various temperatures," Progress in Organic Coatings, vol. 48, no. 2-4, pp. 322-331, 2003.

[15] B. J. Briscoe, P. D. Evans, S. K. Biswas, and S. K. Sinha, "The hardnesses of poly(methylmethacrylate)," Tribology International, vol. 29, no. 2, pp. 93-104, 1996.

[16] P. Kurkcu, L. Andena, and A. Pavan, "An experimental investigation of the scratch behaviour of polymers: 1 . influence of ratedependent bulk mechanical properties," Wear, vol. 290-291, pp. 86-93, 2012.

[17] A. Hernández-Jiménez, J. Hernández-Santiago, A. MaciasGarcía, and J. Sánchez-González, "Relaxation modulus in PMMA and PTFE fitting by fractional Maxwell model," Polymer Testing, vol. 21, no. 3, pp. 325-331, 2002.

[18] E. M. Arruda and M. C. Boyce, "Evolution of plastic anisotropy in amorphous polymers during finite straining," International Journal of Plasticity, vol. 9, no. 6, pp. 697-720, 1993.

[19] F. Zaïri, K. Woznica, and M. Naït-Abdelaziz, "Phenomenological nonlinear modelling of glassy polymers," Comptes Rendus Mecanique, vol. 333, no. 4, pp. 359-364, 2005.

[20] E. Felder and J. L. Bucaille, "Mechanical analysis of the scratching of metals and polymers with conical indenters at moderate and large strains," Tribology International, vol. 39, no. 2, pp. 7087, 2006.
[21] J. L. Bucaille, C. Gauthier, E. Felder, and R. Schirrer, "The influence of strain hardening of polymers on the piling-up phenomenon in scratch tests: experiments and numerical modelling," Wear, vol. 260, no. 7-8, pp. 803-814, 2006.

[22] N. Aleksy, G. Kermouche, A. Vautrin, and J. M. Bergheau, "Numerical study of scratch velocity effect on recovery of viscoelastic-viscoplastic solids," International Journal of Mechanical Sciences, vol. 52, no. 3, pp. 455-463, 2010.

[23] G. Kermouche, J. Rech, H. Hamdi, and J. M. Bergheau, "On the residual stress field induced by a scratching round abrasive grain," Wear, vol. 269, no. 1-2, pp. 86-92, 2010.

[24] J. Rech, G. Kermouche, W. Grzesik, C. García-Rosales, A. Khellouki, and V. García-Navas, "Characterization and modelling of the residual stresses induced by belt finishing on a AISI52100 hardened steel," Journal of Materials Processing Technology, vol. 208, no. 1-3, pp. 187-195, 2008.

[25] S. C. Bellemare, M. Dao, and S. Suresh, "Effects of mechanical properties and surface friction on elasto-plastic sliding contact," Mechanics of Materials, vol. 40, no. 4-5, pp. 206-219, 2008.

[26] G. Kermouche, A. L. Kaiser, P. Gilles, and J. M. Bergheau, "Combined numerical and experimental approach of the impactsliding wear of a stainless steel in a nuclear reactor," Wear, vol. 263, no. 7-12, pp. 1551-1555, 2007.

[27] K. Holmberg, A. Laukkanen, H. Ronkainen, K. Wallin, S. Varjus, and J. Koskinen, "Tribological contact analysis of a rigid ball sliding on a hard coated surface. Part I: modelling stresses and strains," Surface and Coatings Technology, vol. 200, no. 12-13, pp. 3793-3809, 2006.

[28] P. Bertrand-Lambotte, J. L. Loubet, C. Verpy, and S. Pavan, "Understanding of automotive clearcoats scratch resistance," Thin Solid Films, vol. 420-421, pp. 281-286, 2002.

[29] H. Pelletier, C. Gauthier, and R. Schirrer, "Relationship between contact geometry and average plastic strain during scratch tests on amorphous polymers," Tribology International, vol. 43, no. 4, pp. 796-809, 2010.

[30] G. Kermouche, J. L. Loubet, and J. M. Bergheau, "Cone indentation of time-dependent materials: the effects of the indentation strain rate," Mechanics of Materials, vol. 39, no. 1, pp. 24-38, 2007.

[31] G. Kermouche, J. L. Loubet, and J. M. Bergheau, "Extraction of stress-strain curves of elastic-viscoplastic solids using conical/pyramidal indentation testing with application to polymers," Mechanics of Materials, vol. 40, no. 4-5, pp. 271-283, 2008.

[32] B. J. Briscoe, P. D. Evans, E. Pelillo, and S. K. Sinha, "Scratching maps for polymers," Wear, vol. 200, no. 1-2, pp. 137-147, 1996.

[33] D. Chamoret, P. Saillard, A. Rassineux, and J. M. Bergheau, "New smoothing procedures in contact mechanics," Journal of Computational and Applied Mathematics, vol. 168, no. 1-2, pp. 107-116, 2004.

[34] H. Pelletier, C. Gauthier, and R. Schirrer, "Influence of the friction coefficient on the contact geometry during scratch onto amorphous polymers," Wear, vol. 268, no. 9-10, pp. 1157-1169, 2010.

[35] J. Sweeney and I. M. Ward, "A constitutive law for large deformations of polymers at high temperatures," Journal of the Mechanics and Physics of Solids, vol. 44, no. 7, pp. 1033-1049, 1996.

[36] Y. Tomita, "Constitutive modelling of deformation behavior of glassy polymers and applications," International Journal of Mechanical Sciences, vol. 42, no. 8, pp. 1455-1469, 2000.

[37] B. P. Gearing and L. Anand, "On modeling the deformation and fracture response of glassy polymers due to shear-yielding and 
crazing," International Journal of Solids and Structures, vol. 41, no. 11-12, pp. 3125-3150, 2004.

[38] J. S. Bergström, S. M. Kurtz, C. M. Rimnac, and A. A. Edidin, "Constitutive modeling of ultra-high molecular weight polyethylene under large-deformation and cyclic loading conditions," Biomaterials, vol. 23, no. 11, pp. 2329-2343, 2002.

[39] J. Richeton, S. Ahzi, K. S. Vecchio, F. C. Jiang, and A. Makradi, "Modeling and validation of the large deformation inelastic response of amorphous polymers over a wide range of temperatures and strain rates," International Journal of Solids and Structures, vol. 44, no. 24, pp. 7938-7954, 2007.

[40] O. A. Hasan and M. C. Boyce, "A constitutive model for the nonlinear viscoelastic viscoplastic behavior of glassy polymers," Polymer Engineering and Science, vol. 35, no. 4, pp. 331-344, 1995.

[41] E. M. Arruda, M. C. Boyce, and H. Quintus-Bosz, "Effects of initial anisotropy on the finite strain deformation behavior of glassy polymers," International Journal of Plasticity, vol. 9, no. 7, pp. 783-811, 1993.

[42] A. S. Argon, "A theory for the low temperature plastic deformation of glassy polymers," Philosophical Magazine, vol. 28, no. 4, pp. 839-865, 1973.

[43] A. Vautrin, "Etude en traction du processus de relaxation béta du polyméthacrylate de méthyle," Comptes Rendus de l'Academie des Sciences de Paris B, vol. 279, pp. 629-632, 1974.

[44] A. Vautrin, Etude du comportement viscoélastique des solides par la méthode de traction modulée: relaxation secondaire du PMMA [Ph.D. thesis], Université de Nancy I, 1976.

[45] J. Richeton, G. Schlatter, K. S. Vecchio, Y. Rémond, and S. Ahzi, "A unified model for stiffness modulus of amorphous polymers across transition temperatures and strain rates," Polymer, vol. 46, no. 19, pp. 8194-8201, 2005.

[46] M. F. Ashby and D. R. H. Jones, Matériaux : 2. Microstructures et Mise en Oeuvre, Dunod, 1991.

[47] C. G'Sell and J. M. Haudin, Introduction à la Mécanique des Polymères, Institut National Polytechnique de Lorraine, 1995. 

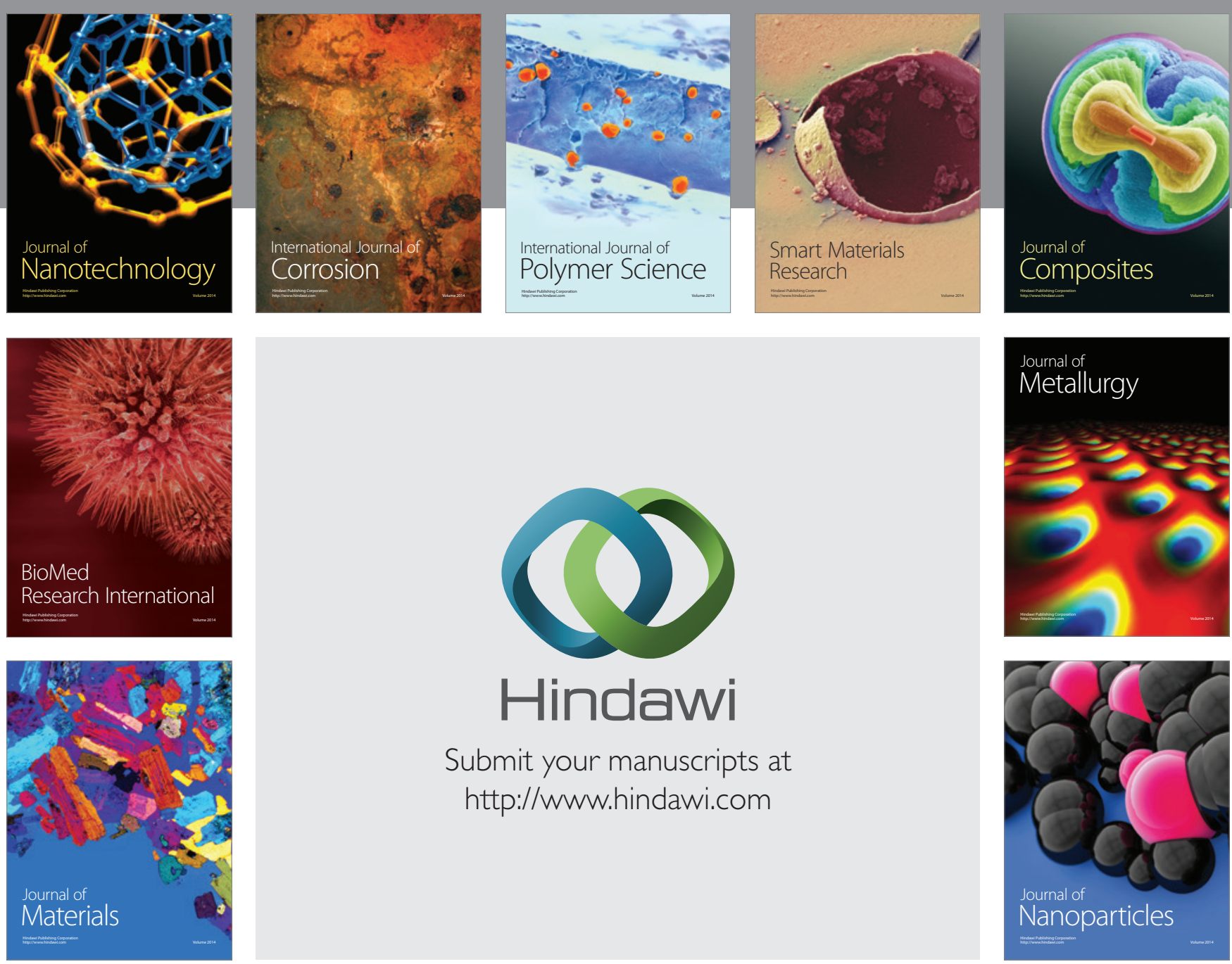

Submit your manuscripts at http://www.hindawi.com
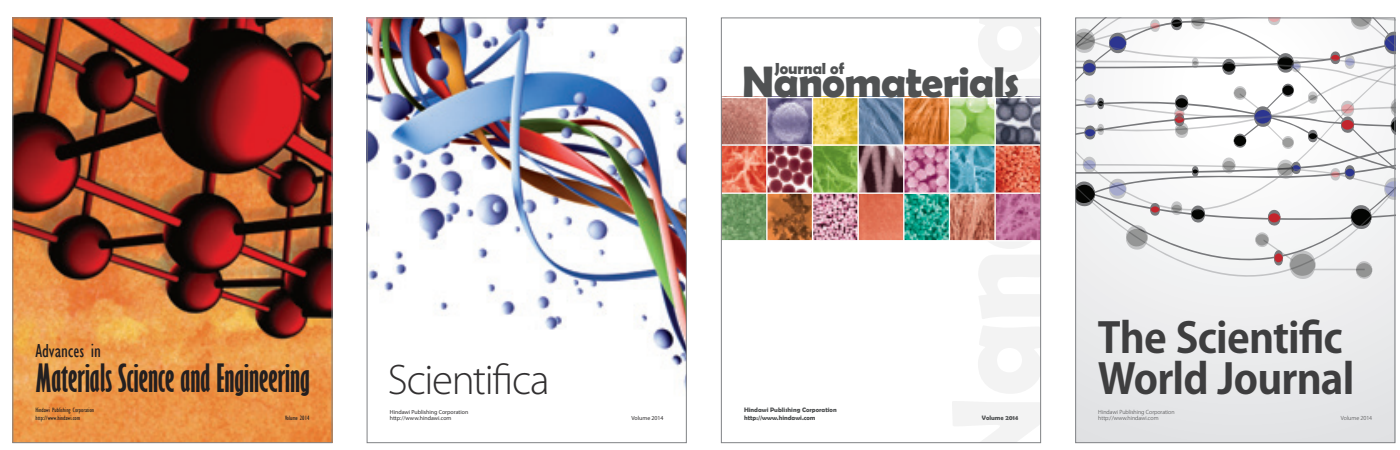

\section{The Scientific World Journal}
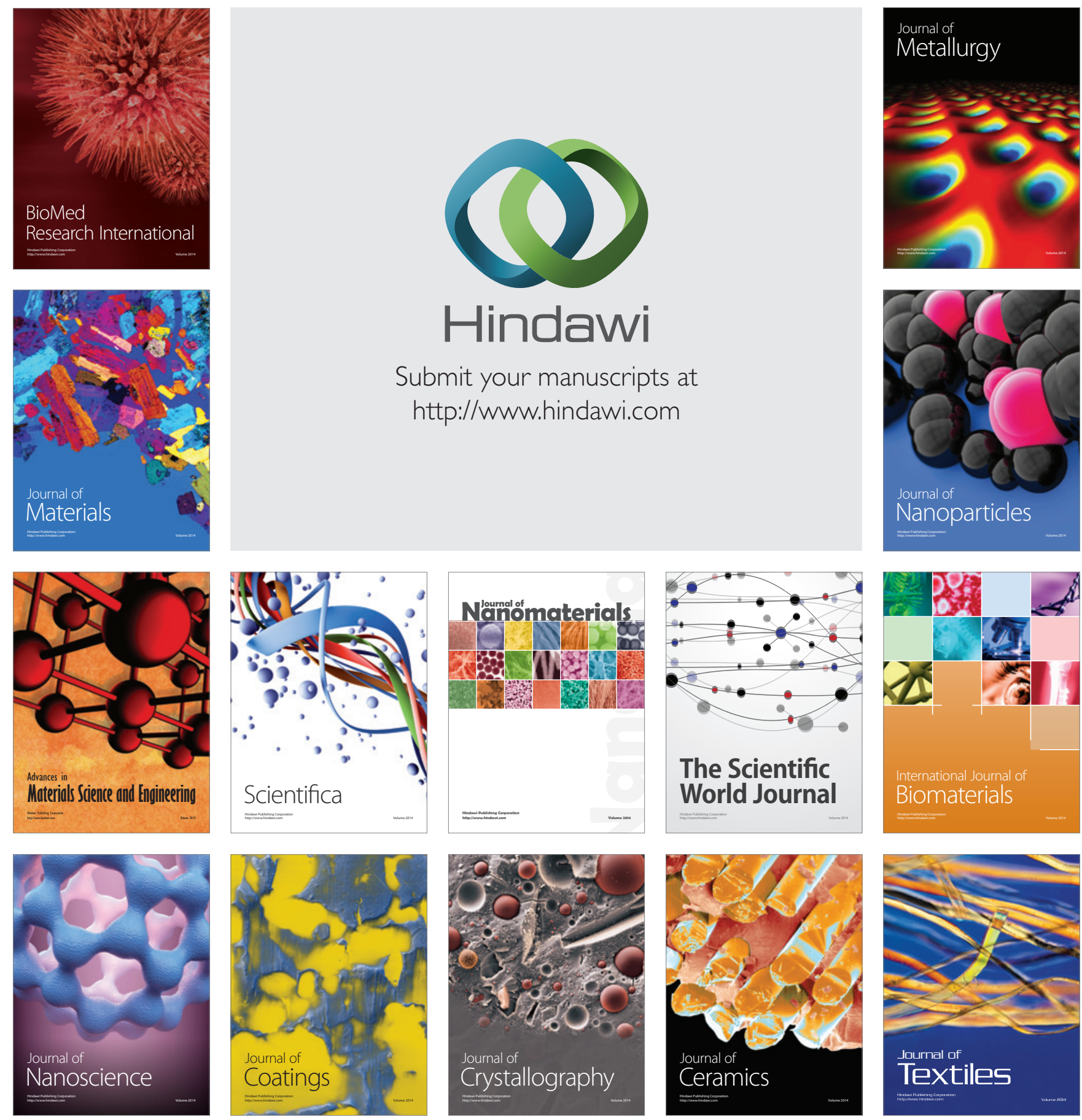